\title{
Desenvolvimento de um Sistema Programável para Reprodução de Trajeto realizado por Robôs Autônomos.
}

\section{João Victor Ramos Faria*, Rodrigo Luiz Ximenes, Talía Simões dos Santos.}

\section{Resumo}

Este trabalho consiste na elaboração de um sistema capaz de reconhecer e armazenar uma dada rota, a fim de possibilitar o movimento autônomo de um robô em um trajeto escolhido. Para o desenvolvimento deste sistema, utilizou-se uma placa Arduino MEGA, módulos Xbee, rodas, motores, sensores e outros componentes eletrônicos e mecânicos de uso geral. A gravação da rota é feita através dos dados dos odômetros acoplados às rodas.

\section{Palavras-chave:}

Microcontrolador, Odometria, Robôs Autônomos.

\section{Introdução}

Com a evolução e o barateamento dos sistemas embarcados, houve um avanço no mercado de dispositivos autônomos. Um exemplo é o aspirador de pó inteligente, que está cada vez mais comum nas casas. A proposta deste projeto é desenvolver um veículo robotizado, capaz de adquirir e gravar dados de movimentação de um determinado trajeto estabelecido pelo usuário e percorrê-lo em um momento posterior de forma autônoma.

Uma pesquisa que serviu de base para este trabalho foi realizada a fim de analisar irregularidades das rampas de acesso ao cadeirante. O monitoramento do deslocamento foi feito através de odômetros de IF acoplados às rodas 1 .

Para o desenvolvimento deste projeto foi utilizada uma placa microcontroladora Arduino MEGA ${ }^{2}$ para acionamento dos motores e comunicações. Também foram utilizados módulos Xbee para transmissão e recepção de dados, rodas, motores, sensores.

\section{Resultados e Discussão}

Primeiramente, 0 robô foi controlado manualmente através de um controle remoto desenvolvido neste trabalho. No trajeto manual, a contagem dos odômetros é enviada à cada segundo para um computador, que os armazena. Posteriormente, no processo de reprodução de trajeto, os dados dos odômetros são enviados de volta ao robô, que os utiliza no algoritmo de reprodução de trajeto desenvolvido. Toda a comunicação sem fio foi realizada através dos módulos Xbee. O robô desenvolvido é ilustrado na Figura 1.

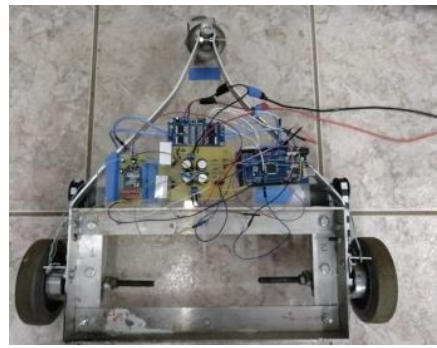

Figura 1: veículo robotizado

Os resultados deste trabalho são baseados nas diferenças entre os deslocamentos manuais e reproduzidos. Utilizando um sistema de coordenadas cartesianas $2 \mathrm{D}$ onde $X$ representa um deslocamento lateral e $\mathrm{Y}$ um deslocamento frontal, foi construída a
Tabela 1, que apresenta os resultados de seis reproduções de um trajeto aproximadamente reto, que foi manualmente traçado. Deslocamentos negativos representam desvios para a esquerda e para trás nos eixos $\mathrm{X}$ e $\mathrm{Y}$, respectivamente, assim como em um sistema cartesiano.

Tabela 1: Erros provindos das diferenças entre o trajeto original e os reproduzidos. Para o trajeto manualmente traçado: $X=3,40 \mathrm{~cm}$ e $Y=1,63 \mathrm{~m}$.

\begin{tabular}{|c|c|c|c|}
\hline Trajetória & $\begin{array}{c}\text { Desloc. } \\
\text { em X (cm) }\end{array}$ & $\begin{array}{c}\text { Desloc. } \\
\text { em Y }(\mathrm{m})\end{array}$ & $\begin{array}{c}\text { Erro } \\
\text { percentual } \\
\text { em Y }\end{array}$ \\
\hline$\# 1$ & 6,60 & 1,552 & $-4,78 \%$ \\
\hline$\# 2$ & $-7,50$ & 1,671 & $2,53 \%$ \\
\hline$\# 3$ & 10,00 & 1,600 & $-0,88 \%$ \\
\hline$\# 4$ & 3,00 & 1,564 & $-4,05 \%$ \\
\hline$\# 5$ & 6,90 & 1,551 & $-4,85 \%$ \\
\hline$\# 6$ & 9,90 & 1,551 & $-4,85 \%$ \\
\hline Média & 4.82 & 1,582 & $-2,98 \%$ \\
\hline
\end{tabular}

É natural a ocorrência de grandes desvios laterais, já que o deslocamento nesta direção foi na ordem de centímetros, ordem essa a mesma da resolução dos odômetros. Já os desvios frontais foram considerados satisfatórios, uma vez que a única referência de reprodução são dos odômetros e não há nenhum sensor de orientação.

\section{Conclusões}

Para curtas distâncias, os resultados indicaram que a reprodução de trajetos utilizando apenas odômetros é satisfatória, o que permite a aplicação desta técnica em diversas aplicações tais como: robôs de monitoramento para segurança, robôs para transporte de materiais, equipamentos domésticos autônomos, entre outras, sem o uso de técnicas de guiamento como linhas de referência visual ou guias metálicos.

\section{Agradecimentos}

Ao CNPq pelo auxílio financeiro.

\footnotetext{
1 Pontes, A. T. A.; Santos, T. S. (2016). Desenvolvimento de um Robô para Análise de Acessibilidade em Ambientes. XXIV Congresso de Iniciação Científica da Unicamp, Campinas, SP, Brasil.

2 Arduino MEGA 2560 Rev3. Disponível em: <https://www.arduino.cc/en/Main/ArduinoBoardMega>. Acesso em: $27 \mathrm{de}$ Janeiro de 2019.
} 